\title{
Accounting Standards No.1, 2, 3 and 4 of Iran and Its Comparative Comparison with International Accounting Standards till 2014
}

\author{
Rashidi Astaneh, Milad ${ }^{1}$ \\ ${ }^{1}$ MSc of accounting course, Islamic Azad University, Tehran South Branch, Iran \\ Correspondence: Rashidi Astaneh, Milad, MSc of accounting course, Islamic Azad University, Tehran South \\ Branch, Iran. E-mail: esfehani.mohamad3@gmail.com
}

Received: July 22, 2016

doi:10.5539/mas.v10n12p206
Accepted: August 12, 2016

Online Published: September 3, 2016

URL: http://dx.doi.org/10.5539/mas.v10n12p206

\begin{abstract}
This article considers the comparative comparison of Iran's accounting standards and international accounting standards till 2014 and studies the accomplished changes after IASB and FASB cooperation. The purpose of this research is to collect the information for researchers in order to help to increase more convergence between Iran's accounting standards and international standards. After comparison of standards, the questionnaires were distributed among accountants community in Iran and they were analyzed by using of Chi-square test. The results indicate that for more convergence, seventeen standards of Iran's accounting standards should be reviewed by standards compilation committee.
\end{abstract}

Keywords: Iran's accounting standards, international accounting standards, IAS, IFRS

\section{Introduction}

Accounting standards whether in national level or international scale have been ordained or are ordained with this purpose that financial information and especially financial statements are provided and presented with defined terms, measurement methods and similar and concordant recognition and applying the desired principles and standards is prevented. Currently, most of the world countries pass from some stages of ordaining and compiling the national standards or accepting the international accounting standards in a manner that providing and presenting financial statements and reports without specified standards don't have meaning. In Iran till before Islamic revolution, unfortunately no work had been done in the field of creating Iran's accounting standards and the first attempts began with formation of accounting institute of national industries organization, program organization and creation of the specialized researches center of accounting and auditing and translation of international accounting standards by this center and the necessary principles were offered to the profession and after that, with formation of auditing organization, this duty was also given to the organization. In relation with compilation of Iran's accounting standards, many attempts in several years and with participation of many groups of experts have been accomplished that has been a difficult work and it deserves to be appreciated. But it should be considered that for presence and participation in global markets, acceptance of international accounting standards and conformity of Iran's accounting standards with it are necessary. The global capitalism thought causes that using of international standards to be generalized and the financial status performance of economic units all around the world to be indicated with similar standards. Naturally, if the decision is on this issue that we have capital exchange with other countries according to the third and fourth economic programs and what has been proposed in general policies of country, our accounting standards should be convergent with international standards.

The purpose of current research and approval of it in the frame of a thesis is to help more convergence with updating Iran's accounting standards through comparing with the newest compiled international standards so that with doing this work, the necessity of revision in Iran's accounting standards by the specialized committee of auditing organization is emphasized. Historically, it has been demanded from the companies to provide their financial statements according to the special financial reporting standards of each country. Consequently, the persons who invest in the companies of different countries should grapple with financial statements according to different financial «languages». In this status, the financial statements of countries often seems similar while it isn't true. Financial statements all are expressed according to the monetary criterion and it seems that in different countries, similar classes are used. Therefore, the users of financial statements may believe that financial 
statements reflect similar financial language, but «the words» have different meanings usually depending on a country in which financial statements are provided. Iran's accounting standards seeks to compile and publish different accounting guidelines in the years of 1994-1996, and in 1999 the set of accounting guidelines was provided and after approval of competent authorities, their implementation during two years in trial form was necessary. With collecting and studying the opinions and suggestions presented about published accounting guidelines and complementary studies, in 2000 in coordination with international accounting standards, 22 standards were compiled and published and the implementation of them was necessary since the beginning of 2001.

IAS: it is the abbreviation of the International Accounting Standards phrase, a set of accounting standards which have been published by international accounting standards committee since 1973 to 2000 .

IFRS: it is the abbreviation of International Financial Reporting Standards phrase, a set of accounting standards which have been published since 2001 by an independent and non-profit organization called international accounting standards board. These standards present more comprehensive instruction than the provisions related to the reporting of some important industries. Currently, more than 100 countries have permitted or necessitated to use of such standards for governmental countries. Using of such companies especially for large companies which have branch in other countries can be important.

\section{The General Methods of Compilation of Standard}

Four general solutions in the world level have been applied about ordaining and compiling the national accounting standards which are briefly:
A) Compilation of standards by professional communities
B) Compilation of standards by professional committees and approval of them by general authorities
C) Compilation of accounting standards by the selected authority of government
D) Acceptance of international accounting standards

\subsection{The Research Background}

In the field of scales and standards, the researches accomplished in Iran can be divided into two general groups: first group includes the researches that have been selected according to the ambiguity or importance of some standards in selective and case form in which the researcher after proposing the problem, studies and criticizes it (like: the standard cash flow statement existing in Iran in scales with international standard- Moradzadeh, Mehdi), but the second group includes the researches that have studied the scales and all standards and clarifies the differences existing between Iran's standards and international standards by comparing the standards clause by clause.

\subsection{Domestic Background}

Currently, the last research which has compared all Iran's accounting standards with international accounting standards refers to 2004, when the number of compiled standards of Iran didn't exceed from 25 standards. During these years, new standards have been compiled and some of the previous standards have been also revised and more important than all, the agreement accomplished between the compilation board of international and American standards in compilation of common standards has caused much transformation in international accounting standards. In the following, some of the accomplished researches with their results are presented:

1) «The relation between compilation of accounting standards and accounting information quality», Saghafi, Ali; Ebrahimi, Ebrahim. In this article, it has been mentioned that there is this belief that whatever the quality of financial reports is increased and more valid standards and criteria are used in providing and presenting the reports, the information risk will be reduced. The accountability standards are compiled aligned with the purpose of increasing the accounting information quality and playing the role of accounting informing in desired manner. In this research, this issue has been studied that whether the compilation and implementation of accounting standards have caused to increase the accounting information quality or not. In this article also for hypothesis test, multi-variable Regression method has been used. The test results of models totally indicated that implementation of standards only in the stability model has been accompanied with relative improvement of additional stability while in other models, standards couldn't have significant effect.

2)Studying the cultural values in Iran and the possibility of achieving the purpose of presenting the international accounting standards in desired manner, Dr Noroush, Iraj.

In this article, it has been mentioned that Iran as a country with gregarious culture features, much distance of 
power and legal control, severe elusion from indeterminacy and vast establishment of legal institutes, governmental and political economy like many developing countries has much difference in the cultural, political legal and economic fields with other countries. Accounting profession as a subculture can not act similarly in the countries with different cultures. Stipulation of theoretical frame of accounting guidelines committee in Iran according to the desired (fair) presentation of financial statements has been in contrariety with legal necessity in using of legal (fiscal) offices for desirous reporting and committee manipulation in some methods inserted in international accounting provinces (like elimination of the LIFO method in assessment of goods inventory ) and it has complicated the desired presentation of performance results and financial status of commercial units. At current research a sample of MSc and BA students of accounting course informed of theoretical frame of international accounting standards and standard No.1 was selected. The obtained results indicate Iran' accounting statements can not supply the axial purposes of international accounting standards (fair presentation of financial statements).

3) Coordination of accounting standards

Dr Khoshtinat, Mohsen. Rahimian, Nezameddin.

This article after presentation of coordination definition and background discusses and studies different issues such as advantages, problems, key variables and accelerator factors of coordination process and introduces committees, organizations, groups and unions which attempt for international coordination of accounting.

4) A step toward implementation of international accounting standards

\section{Asna Ashari, Hamideh; Beigi, Mostafa Ahmadkhan}

This article discusses about cases such as the causes of difference of national accounting standards of different countries, quality of international accounting standards in comparison with financial accounting standards of America, coordination advantages and the role of stock exchange of America in the coordination process.

\subsection{Foreigner Background}

1) Investigation in the field of compilation of international accounting standards, black box of IFRS

This article was presented in 2010 by Corinne Cortese and Helen Irvine and it was a research about the influence of powerful companies in formation of international accounting standards especially about a project that the international accounting standards board has about the standard No.6 (exploration exploitation of mineral sources). In this standard, the board suggested instead of calculation of total cost, the successful attempt method to be placed as the basis of pre-production costs. But despite of confirmation of the majority of members, the results of this method didn't change anything. In this article, it was expressed that some companies have been effective on the manner of determining the management of pre-production costs.

2-The amount of convergence of national accounting standards with international reporting standards

Xiaohui Qu and Guohua Zhang, two Chinese researchers in 2010 compared the accounting standards of China with international accounting standards. In this article, it has been mentioned that the purpose of compilation of integrated accounting standards is to reach the global convergence and with regard to the importance of this issue, these researchers have measured and assessed the convergence method. Also, another purpose of these researchers was to find a way for more convergence of accounting standards of China and international reporting standards.

3) Lack of coordination with international accounting standards

Kushang Zhang \& et al have considered lack of coordination existing between the method proceeded by accounting standards compilers in China and international accounting standards. One sample of this lack of coordination is to accept the benefits union method in China country, in the event that this method has been eliminated by international accounting standards board. This research which has been accomplished in 2009 indicates this issue that the accounting standards compilers in China have proceeded a method which is in contrariety with international accounting standards board.

4) International financial reporting standards and information quality of financial statements

Iatridis, George has written an article in the field of acceptance of international financial reporting standards and movement from GAAP toward applying IFRS in England and in this research, he seeks to answer this question that whether acceptance of financial reporting standards causes to increase the information quality or not and finally he proved that acceptance of such standards causes to reduce lack of symmetry of information and better measurement of it, consequently the investors and users can make decision with more certainty. 


\subsection{Statistical Community, Sample Size, Sample Range}

A set of persons, events, objects, places and affairs that have one or several common features is called statistical community. Usually in each research, the community includes all persons or cases that researcher has interst to generalize the research results to them. The statistical community of current research includes all accountants who are the members of formal accountants community of Iran.

\subsection{Sampling Method and the Approximate Sample Size}

On top of planning of each study or research, this question is proposed: how much is the sample size? This question is an important issue and it never be accounted small. Selecting a sample larger than needed extent for achieving the intended results causes to waste the sources while selecting very small samples often propels the researcher to the results that don't have practical use. Since in non-trial researches, the purpose of researcher is often to estimate the community mean and with regard to this issue that the distribution of studied variables may not be normal, it has been recommended that the sample size to be selected more than $30^{1}$. In this research, since the studied traits are qualitative, therefore variance changes limits are used in qualitative trait. The limits of these changes are in the range of 0 to 0.25 and the maximum sample size is resulted according to the most dispersion size. Therefore, the following formula is used for determining the sample size.

$$
\text { Sample size } \quad n=\frac{z_{\alpha}^{2} p q}{d^{2}}
$$

$\mathrm{Z}=$ the amount of normal variable of corresponding unit,

$\mathrm{d}=$ limitative error (the most permitted error),

$\alpha=$ critical level

Also in this formula, $\mathbf{P}$ estimate of the variable trait ratio is $q=1-p$ by using of previous studies. If the amount of $\mathrm{p}$ isn't available, it can be selected equal to 0.50 . In this state, the variance amount reaches to its maximum namely 0.25 .

Making decision about the effect size of $d$, the needed effect size for the statistical assumption test related to a sample is specified in the behavioral sciences researches.

The amount of $\mathrm{d}=0.02$ is usually called the small effect size and the amount of $\mathrm{d}=0.08$ or $\mathrm{d}=0.10$ is called the large effect size. With regard to the conditions of this research, the confidence level and limitative error have been considered in order $95 \%$ and $10 \%$.

Also for calculation of critical level, the confidence level should be subtracted from (No. 1).

$\propto=1-0 / 95$

With regard to the above formula, the number of 0.05 is obtained for Alpha. For calculation of $Z \frac{\alpha}{2}$ in equation,

with referring to the statistical tables, the number of 96.1 is calculated.

With given explanations, the sample size can be determined:

$$
n=\frac{1 / 96^{2} \times 0 / 25}{0.1^{2}}=96
$$

\subsection{The Information Collection Method: Field. Library}

As it was referred before, in this research, the collected data have been in qualitative form and they have been measured with nominal scale (using of number for nomination and classification of qualitative data), for data collection, a kind of questionnaire has been used and for measurement of the questionnaire variable, Likert scale which is one of the most popular measurement scales has been used.

\subsection{Information Collection Tool}

For information collection, a kind of questionnaire has been used and for measurement of the questionnaire variable, Likert scale which is one of the most popular scales of measurement has been used. Also this questionnaire has been classified in four columns that the responder indicates the amount of his/her agreement with each one of these phrases. These four columns are: 1.it has no conformity at all, 2 .it has conformity to some extent, 3.it has conformity in most of clauses, and 4.it has complete conformity. 
Due to this issue that this research with utilizing today's knowledge from library method and theoretical discussions has been proposed and it has studied the differences between Iran's accounting standards and international standards for rejection or confirmation of them, current research in terms of the research purpose is an applicable kind and in terms of data and information collection, it is a survey research kind of Delphi kind. Also the methodology is analogical-inductive. The methodology includes two stages: 1) library and computer studies for compilation of theoretical principles. 2) Field studies for data collection. Also in this research, the collected data have been in qualitative form and they have been measured with nominal scale (using of number for nomination and classification of qualitative data). Therefore, for data test, non-parametric tests are needed and among different methods, Chi-square method has been selected for proving the hypotheses.

\section{The Research Hypotheses}

With regard to the purposes and problems of the research, the following hypotheses are proposed so that after information collection, the confirmation test or the hypothesis rejection are accomplished.

The first hypothesis) the accounting standards N0.2,1 of Iran don't conform to the related international standards (IAS) completely.

The second hypothesis) accounting standards No.4,3 conform to the related international standards (IAS) completely.

\subsection{Data Analysis}

After determining the research problem and methodology, the data collection stages have been passed and then the analysis has been considered in order to specify the status of the research hypotheses (confirmation or rejection of hypotheses). The purpose of data analysis is to determine the cause-effect relation between the intended phenomena. The validity of this questionnaire was studied on 15 cases of statistical community in trial form, with analysis by SPSS15, the number of 0.72 has been obtained which is accounted an acceptable amount.

All questions have been proposed in the frame of a questionnaire for proving all hypotheses that for the hypotheses test in order: questions 1 to 17 are for the first hypothesis test, questions 18 to 27 are for the second hypothesis test and questions 28 to 30 are for third hypothesis test.

\subsection{The First Hypothesis Test}

$\mathrm{H} 0=$ the accounting standards No.1, 2 of Iran conform to the related international standards (IAS) completely.

$\mathrm{H} 1=$ the accounting standards No.1,2 don't conform to the related international standards (IAS) completely.

\begin{tabular}{|l|l|l|l|l|l|l|l|l|l|}
\hline & $\mathrm{a} 1$ & $\mathrm{a} 2$ & $\mathrm{a} 3$ & $\mathrm{a} 4$ & $\mathrm{a} 5$ & $\mathrm{a} 6$ & $\mathrm{a} 7$ & $\mathrm{a} 8$ & $\mathrm{a} 9$ \\
\hline Chi-Square(a,b,c,d) & 97.916 & 173.084 & 93.495 & 78.968 & 204.242 & 91.681 & 185.042 & 125.589 & 217.800 \\
\hline Df & 2 & 3 & 2 & 2 & 3 & 2 & 3 & 3 & 3 \\
\hline Asymp. Sig. & .000 & .000 & .000 & .000 & .000 & .000 & .000 & .000 & .000 \\
\hline
\end{tabular}

\begin{tabular}{|l|l|l|l|l|l|l|l|l|}
\hline & $\mathrm{a} 10$ & $\mathrm{a} 11$ & $\mathrm{a} 12$ & $\mathrm{a} 13$ & $\mathrm{a} 14$ & $\mathrm{a} 15$ & $\mathrm{a} 16$ & $\mathrm{a} 17$ \\
\hline Chi-Square(a,b,c,d) & 102.463 & 129.747 & 102.084 & 90.589 & 75.558 & 115.537 & 57.747 & 89.516 \\
\hline Df & 2 & 2 & 2 & 2 & 2 & 2 & 2 & 2 \\
\hline Asymp. Sig. & .000 & .000 & .000 & .000 & .000 & .000 & .000 & .000 \\
\hline
\end{tabular}

With regard to the statistical tables, if $\mathrm{H} 0$ is valid in confidence level of $95 \%$, the observed results will be improbable, consequently enough evidences are obtained for acceptance of hypothesis 1 (H1).

The second hypothesis test:

$\mathrm{H} 0=$ the accounting standards No.3,4 don't conform to the related international standards (IAS).

$\mathrm{H} 1=$ the accounting standards No.3,4 conform to the related international standards (IAS).

\begin{tabular}{|l|l|l|l|l|l|l|l|l|l|l|}
\hline & $\mathrm{a} 18$ & $\mathrm{a} 19$ & $\mathrm{a} 20$ & $\mathrm{a} 21$ & $\mathrm{a} 22$ & $\mathrm{a} 23$ & $\mathrm{a} 24$ & $\mathrm{a} 25$ & $\mathrm{a} 26$ & $\mathrm{a} 27$ \\
\hline Chi-Square(a,b,c,d) & 204.579 & 166.821 & 76.053 & 155.958 & 161.200 & 59.211 & 62.411 & 139.979 & 198.179 & 150.337 \\
\hline df & 3 & 2 & 1 & 2 & 2 & 1 & 1 & 2 & 3 & 2 \\
\hline Asymp. Sig. & .000 & .000 & .000 & .000 & .000 & .000 & .000 & .000 & .000 & .000 \\
\hline
\end{tabular}


With regard to the statistical tables, if $\mathrm{H} 0$ is valid in confidence level of $95 \%$, the observed results will be improbable. Consequently, enough evidences are obtained for acceptance of hypothesis 1 (H1).

\section{Conclusion}

In this study, it was mentioned that accounting standards have numerous advantages that manifest its benefits more than its costs. The following cases are some of the accounting standards advantages:

- Equipping the accounting profession with a set of useful applicable rules

- Unavoidable promotion of accountants work quality

- Creating the possibility of accountants' resistance against the managers' pressure about application of improper accounting methods

In the following, after mention of the methods related to the compilation of accounting standards and also accounting standards status in some of advanced countries, the necessity of convergence was emphasized and it was explained that for comparativeness of information, we need coordinated international standards. But there are obstacles in this route that some of them are as follows:

- Users in different countries have different needs

- Difference between the needs of multi-nationality companies and small commercial units in developing countries

- Much cost of obligating the companies to change the accounting principles or having separated accounting systems for transboundary supplies

After these cases, the discussion of convergence project of IASB and FASB was considered and the problem of acceptance of changing standards for the countries that translate the standards or like Iran that localizes the international standards was proved with confirmation of the first hypothesis. A hypothesis in which it had been claimed that the standards No.1,2 don't conform to the related international standards (IAS) completely. Since the committee policy in the compilation of standards is to move toward international accounting standards, with considering the environmental realities, it is expected from this committee to seek to eliminate or reduce these differences with necessary acts and mechanisms. About other standards $(3,4)$, currently the convergence has been kept. But since the project continues, it can be expected that in future years, some changes to be accomplished in international standards, consequently this affair will cause the distance of Iran's accounting standards with international standards.

\section{Suggestions}

In relation with the first hypothesis, the following suggestions are presented for more researches:

1) Studying the causes of delay in revision of Iran's accounting standards on behalf of the compiler committee of standards

2) Studying the necessity of revision in investments accounting standard

\subsection{Suggestion About the Future Researches}

1-Since the project of synchronization of international accounting standards with America's financial accounting standards is still being done and creation of more changes in future years isn't far from expectation, some researches can be done with similar titles but for another time period.

2-The criterion of decision-making of auditing organization committee in the compilation of standards is the opinion of majority. This mechanism in compilation of standards is similar with the mechanisms of valid professional authorities. The organization has significant problem in the opinion poll. Studying the causes of lack of participation of country's accounting community and following it presentation of new opinion poll techniques can be considered as a research.

3-Studying the causes of some changes in international standards which have been accomplished by the committee of compilation of Iran's standards, for example national standard No.2 of the cash funds flow statement has classified the cash flows into 5 chapters.

4-Comparison of theoretical frame of accounting and financial reporting of Iran with international financial reporting.

\section{References}

Adel, A., \& Momeni, M. (2008). Statistic and its application in management. Samt publication of Tehran (11th 
Ed.).

Asna, A., \& Hamideh (2008). A step toward implementation of international standards. Auditor Journal, Auditory Organization Publication, 42.

Estehghari, M. (2010). The role and importance of accounting standards in financial reporting. Audit Journal, Auditory Organization Publication, 48.

Bostanian, J. (2006). Multilateral opinion to the accounting standards. Audit Journal, Auditory Organization Publication, 33.

Jafari, M. (1994). International similarity of financial reports. Scientific-investigative journal of accounting and auditory studies, Tehran University, 2.

Dehghani, T. (2008). Transboundary supply of stock exchange and the necessity of coordination of accounting standards. Accountant Journal, Assembly of Expert Accountants of Iran, 197.

Differences between domestic accounting standards and IAS. (2007). Measurement, determinants and implications, Yuan Ding, Ole-Kristian Hope, Thomas Jeanjean Herve' Stolowy. Journal of Accounting and Public Policy, 26.

Richard, B., Yuri, B., \& Qiusheng, Z. (2009). Disharmony in international accounting standards setting: The Chinese approach to accounting for business combinations. School of Economics and Management. Beijing Jiaotong University, China.

Corinne, C., \& Helen, I. (2010). Investigating international accounting standard setting: The black box of IFRS 6. Research in Accounting Regulation, 22(2), 87-95.

International Financial Reporting Standards and the quality of financial statement information. (2010). George Iatridis. International Review of Financial Analysis, 19(3), 193-204.

Qu, X. H., \& Zhang, G. H. (2010). Measuring the convergence of national accounting standards with international financial reporting standards: The application of fuzzy clustering analysis. School of Management, Xiamen University, Xiamen, Fujian.

International Financial Reporting and Accounting Standard. (2016). Retrieved from http://www.IASB.org

IAS 1 (2009). Presentation of Financial Statements. This version was issued in September 2007 and includes subsequent amendments resulting from IFRSs issued up to 30 November 2008.

IAS 2 (2009). Inventories This version includes amendments resulting from IFRSs issued up to 31 December 2008. IFRS 3 Business Combinations This version was issued in January 2008.

Note.

Note. 1 Adel, Azar; Momeni, Mansour, statistic and its application in management, Samt publication of Tehran, 2008.

\section{Copyrights}

Copyright for this article is retained by the author(s), with first publication rights granted to the journal.

This is an open-access article distributed under the terms and conditions of the Creative Commons Attribution license (http://creativecommons.org/licenses/by/4.0/). 